\title{
The Contributions of Edwin J. Thomas
}

\author{
Srinika Jayaratne \\ University of Michigan
}

Edwin J. Thomas retired from the University of Michigan School of Social Work in 1994 after an exceptional and distinguished career. Ed received his M.S.W. from Wayne State University and his Ph.D.in Social Psychology from the University of Michigan. He moved directly into a faculty position in the School of Social Work, and served the School and the University for over 35 years. Retirement, for Ed, simply means more time to follow his avocation, reading and writing, and promising to learn how to use the information highway. The profession has benefited immensely from his writings, and we will undoubtedly benefit even more in the near future.

Dr. Thomas's contributions to the profession are hard to summarize. As a former student and colleague, I have taken the liberty of identifying what I consider to be his most significant contributions. These may not be what Ed himself or others may identify, but, in my opinion, these are contributions that have led to some fundamental changes in social work education and professional practice. Briefly, my comments reference his work on role theory and the impact of behavioral science theory on practice, social learning theory and behavior modification, empirical practice and relevant methodologies, and his most recent work on design and development in intervention research.

In 1966, Biddle and Thomas (1966) introduced a book titled Role Theory: Concepts and Research. This book was published at a time when role theory was in search of an identity, was not widely recognized, and was essentially a new field of inquiry. Role theory took on as its domain of study the nature of complex human behavior. As such, role analysts examined questions related to socialization and social interdependence; the nature, characterization, and the organization of position; as well as a variety of other behaviors and attributional elements, which can be explored within the broad context of the individual in the social context.

In one of his earlier efforts related to role theory, Dr. Thomas examined the relationship between the size of an organization and the behavior of its

\footnotetext{
Author's Note: Correspondence may be addressed to Srinika Jayaratne, School of Social Work,
} University of Michigan, Ann Arbor, MI 48109.

Research on Social Work Practice, Vol. 5 No. 4, October 1995 404-410

C 1995 Sage Publications, Inc. 
members (Thomas, 1959). This study compared the role conceptions, the role consensus, and the quality of work of welfare workers in different size organizations. What is interesting in the study is the very use of these concepts. Role consensus and role conception, terms that are in common use today, were in a sense defined in the context of this study. This study also reflects on an agenda yet to come. In examining the quality of work performance, Dr. Thomas notes that it is "possible to learn about the cognitive aspects of performance through evidence of the analytic skill of workers as indicated by their ability, first, to identify problems of families and, second, to propose appropriate treatment plans"' (Thomas, 1959, p. 32). It is clear that he was thinking more along the path of the potential benefits of behavioral specificity of problems and the specification of treatment plans and protocols.

Broadly speaking, Thomas's work in role theory laid the foundation for his continued efforts to bring knowledge from the behavioral and social sciences into the profession of social work. Thus, he followed this initial conceptual work with writings addressing issues relevant to the practice of group work, publishing such articles on group goals and individual goals (Thomas, 1960) and models of group problem solving (Thomas \& Fisk, 1961). The role perspective was then broadened even further, by examining the context of the clinical interview and conceptualizing the interview as an experimental process (Thomas, 1962; Thomas, McLeod, \& Hylton, 1960). "Role playing" was adapted in one of these studies for the purpose of studying and measuring the performance of caseworkers in the casework interview (Thomas, McLeod, \& Hylton, 1960, p. 52), a novel and creative use of a "training device" in those early years of research on group work.

A common theme throughout this early work was the application of social science theory to social work practice. This integration of social science and social work has remained a cornerstone, if not the keystone, in Dr. Thomas's research and writing. In 1967, the profession was introduced to the book Behavioral Science for Social Workers (Thomas, 1967a). In the foreword to this work, Fedele Fauri notes that "the infusion of behavioral science into social work has been one of most significant developments in social work education in recent years" (p. v). Few would argue the veracity of this observation. By weaving together a closely edited book that examined the contributions of behavioral science to the profession through the examination of roles, group and family processes, as well as organizational factors and practice processes, the world of social work practice was essentially exposed to new ways of thinking. This book, in my opinion, redefined the content of the human behavior and social environment curriculum in schools of social work. 
One of the most relevant and lasting contributions of Dr. Thomas can be cited in his efforts to introduce the profession to social learning theory and behavior modification. In 1967, Thomas published The Socio-Behavioral Approach and Applications to Social Work, (Thomas, 1967b) followed by a series of research-based articles addressing the relevance and import of behavioral theory and techniques. Reid (1994) summarized the impact of this work:

In the mid-1960s, faculty and doctoral students at the University of Michigan School of Social Work, under the leadership of Edwin Thomas, began to experiment with the new behavioral methods that had begun to emerge a decade earlier in clinical psychology and psychiatry. In a series of dramatic and controversial presentations at the 1967 Annual Program Meeting of the Council on Social Work Education, this group unveiled their socio-behavioral approach to social work. (p. 168)

With challengers and detractors constantly vigilant and often openly critical, it was becoming clear that if behavioral theory was to be accepted, its effectiveness must be demonstrated. However, it was not enough to present data and outcome studies, it was now necessary to help the individual practitioner gather the data and systematically assess his or her own effectiveness. Effective practice must somehow be grounded in the individual practitioner. As foreign and tumultuous as the introduction of this "new" theory and related technologies appeared, it reflected the principles and paradigms of the profession's founders. According to Reid (1994), Mary Richmond and Florence Hollis viewed social work as both science and art, a considered and rational process, and one that can be examined systematically. This perspective embodied the processes and practices being promoted by Thomas and his colleagues.

Single-case methodology was concomitant with behavioral practice. To be a "good" behavioral practitioner meant being a knowledgeable consumer and applicant of single-case methodology as well as empirical practice in the broad sense. Once again, Dr. Thomas was in the forefront of an emerging field, the empirical practice movement, but this time perhaps more as a teacher. Thomas's classrooms at Michigan became the nexus. One can only speculate about the influence of his students, some of whose work is represented in this issue. At a personal level, these courses had a tremendous influence on my own career. Without a doubt, my interest in practice evaluation and the eventual publication of the book Empirical Clinical Practice (Jayaratne \& Levy, 1979), which I coauthored with Rona Levy (a classmate), emerged from these experiences. In fact, virtually all of the authors in this issue have made substantial contributions in the area of empirical practice. 
However, in an article titled "Research and Service in Single-Case Experimentation: Conflicts and Choices" (Thomas, 1978), Thomas took the empirical practice movement to task. He concluded that: (a) the requirements of direct service often interfere with single-case methods; (b) the requirements of single-case methods often interfere with service; and (c) because combining research and practice in this context involves threats to both, single-case experimentation should be avoided. Predictably, those who took issue with Thomas were his own students (see, for example, Gambrill \& Barth, 1980). Although this debate has led to a closer examination of the pros and cons of single-case methodology, it also brought the whole notion of empirical practice in to the forefront. In fact, "systematic evaluation of practice" is now an accreditation standard (Council on Social Work Education, 1988), and the Report of the Task Force on Social Work Research (1991) stated that "students need more experience that integrate practice and research" (p. 20). The relevance of this debate will become even more central with the impending issues of managed care and contractual services.

Perhaps issues arising from this debate, and critical thinking about the nature and character of clinical practice and relevant methodology, led to emergence of "design and development" and "intervention research." Advanced concurrently by Thomas (1984) and Jack Rothman (1980), and further elaborated jointly by these two authors (Rothman \& Thomas, 1994), the proposed methodology directly addresses the issues raised by the Task Force on Social Work Research. As Reid (1994) observes, "their formulation provides systematic methods of using research in the design, development, testing, and dissemination of practice programs" (p. 180). In fact, intervention research methodology as described by Rothman and Thomas not only provides a cogent and distinct conceptual model for researchers interested in the design and development of practice, it also provides a well-articulated framework for action. Rothman and Thomas (1994) describe the purpose of design and development "as a problem-solving process for seeking effective intervention and helping tools to deal with given human and social difficulties.... Its goal is to produce workable human service technology, rather than generalizable knowledge per se" (p. 12).

Two major research awards, Unilateral Family Treatment for Alcohol Abuse from 1980-1990, funded by the Psychosocial Research Branch of the National Institute of Alcohol Abuse and Alcoholism, and Intervention Research for Mental Health from 1984-1989, funded by the National Institute of Mental Health, provided the empirical underpinnings as well as the laboratory for Thomas's work on design and development. The research on unilateral family therapy, whereas innovative and perhaps provocative in its 
own right, has produced some valuable clinical tools and methodologies. The purpose of this research program was to develop a treatment model whereby spouses of uncooperative alcohol abusers could be assisted to help their partners enter treatment and reduce drinking. The treatment program used a tripartite conceptual framework that first focused on individual coping, then looked at interaction with an emphasis on family functioning, and finally considered the context with a focus on a third party. "A major feature of the unilateral approach is a conception of the role of the cooperative family member as client as well as mediator of change for the uncooperative family member" (Thomas, Santa, Bronson, \& Oyserman, 1987, p. 148). This research has produced perhaps one of the most intensive examinations of working with uncooperative clients, and the use of confrontation as a practice technique (see, for example, Thomas, 1994; Thomas, Adams, Yoshiokoa, \& Ager, 1990). The unilateral project has also provided the profession a series of well-developed clinical tools in the form of rapid assessment instruments to assess the quality of treatment mediation, life distress, sobriety influence, and enabling (Corcoran \& Fischer, 1995, Thomas \& Ager, 1995; Thomas, Yoshiokoa, \& Ager, 1995a, 1995b, 1995c).

Dr. Thomas has, by any definition, been one of the most productive, innovative, and influential scholars in the social work profession. There are few scholars, if any, who have had as significant an impact on so many domains central to the mission of social work education. His work on bridging the gap between the social and behavioral sciences with the theoretical paradigms extant in the profession led to many innovations. Perhaps the most distinct illustration is the infusion of sociobehavioral theory into the professional knowledge base. His substantive contributions are even more impressive when one considers both the breadth and depth of this work. He has been identified as the single most important author to introduce concepts related to empirical clinical practice into the profession. On one hand, his work on single-subject designs can be viewed as another example of bringing in knowledge from the behavioral sciences into the practice of social work. On the other hand, the introduction of concepts and methodology related to design and development and intervention research truly promotes the profession's practice research agenda to another level. Finally, his contributions to clinical practice are best captured by his early work on behavioral interventions and his most recent work on unilateral family therapy. The latter underscore his consistent attention to the interplay between social science research and innovations in clinical practice.

The collection of articles published in this special issue honoring Edwin Thomas addresses many of the issues I have identified as being central to his 
work at some point in his career. The fact that it represents the current work of his students simply reinforces the intellectual impact of his readings and teachings.

\section{REFERENCES}

Biddle, B. B., \& Thomas, E. J. (Eds.). (1966). Role theory: Concepts and research. New York: Wiley.

Corcoran, K., \& Fischer, J. (Eds.). (1995). Measures for clinical practice (2nd ed.). New York: Free Press.

Council on Social Work Education. (1988). Handbook of accreditation standards and procedures. Alexandria, VA: Author.

Gambrill, E. D., \& Barth, R. P. (1980). Single-case study designs revisited. Social Work Research \& Abstracts, 16, 15-20.

Jayaratne, S., \& Levy, R. L. (1979). Empirical clinical practice. New York: Columbia University Press.

Reid, W. J. (1994). The empirical practice movement. Social Service Review, 64, 165-184.

Report of the Task Force on Social Work Research. (1991). Building social work knowledge for effective services and policies: A plan for research development. Washington, DC: National Institute of Mental Health.

Rothman, J. (1980). Social $r$ \& d: Research and development in the human services. Englewood Cliffs, NJ: Prentice-Hall.

Rothman, J., \& Thomas, E. J. (Eds.). (1994). Intervention research: Design and development for human service. New York: Haworth.

Thomas, E. J. (1959). Role conceptions and organizational size. American Sociological Review, 24, 30-37.

Thomas, E. J. (1960). Group goals and the group's goals for the member. Human Relations, 13, 333-344.

Thomas, E. J. (1962). Experimental analogs of the casework interview. Social Work, 7, 24-31.

Thomas, E. J. (Ed.). (1967a). Behavioral science for social workers. New York: Free Press.

Thomas, E. J. (1967b). The socio-behavioral approach and applications to social work. New York: Council on Social Work Education.

Thomas, E. J. (1978). Research and service in single-case experimentation: Conflicts and choices. Social Work Research and Abstracts, 14, 20-32.

Thomas, E. J. (1984). Designing interventions for the human service professions. Beverly Hills, CA: Sage.

Thomas, E. J. (1994). The unilateral treatment program for alcohol abuse: Background, selected procedures and case applications. In J. Rothman \& E. J. Thomas (Eds.), Intervention research: Design and development for human service (pp. 427-448). New York: Haworth.

Thomas, E. J., Adams, K. B., Yoshiokoa, M. R., \& Ager, K. B. (1990). Unilateral relationship enhancement in the treatment of spouses of uncooperative alcohol abusers. American Journal of Family Therapy, 18, 334-345.

Thomas, E. J., \& Ager, R. D. (1995). The Spouse Treatment Mediation Inventories (STMI). In K. Corcoran \& J. Fischer, (Eds.), Measures for clinical practice (2nd ed., pp. 190-195). New York: Free Press. 
Thomas, E. J., \& Fink, C. (1961). Models of group problem solving. Journal of Abnormal and Social Psychology, 63, 53-63.

Thomas, E. J., McLeod, D. L., \& Hylton, L. F. (1960). The experimental interview: A technique for studying casework performance. Social Work, 5, 52-59.

Thomas, E. J., Santa, C., Bronson, D., \& Oyserman, D. (1987). Unilateral family therapy with the spouses of alcoholics. Journal of Social Service Research, 10, 145-162.

Thomas, E. J., Yoshiokoa, M. R., \& Ager, R. D. (1995a). The Life Distress Inventory. In K. Corcoran \& J. Fischer (Eds.), Measures for clinical practice (2nd ed., pp. 127-130). New York: Free Press.

Thomas, E. J., Yoshiokoa, M. R., \& Ager, R. D. (1995b). Spouse Sobriety Influence inventory (SSII). In K. Corcoran \& J. Fischer (Eds.), Measures for clinical practice (2nd ed., pp. 183-189). New York: Free Press.

Thomas, E. J., Yoshiokoa, M. R., \& Ager, R. D. (1995c). The Spouse Enabling Inventory (SEI). In K. Corcoran \& J. Fischer (Eds.), Measures for clinical practice (2nd ed., pp. 177-182). New York: Free Press. 